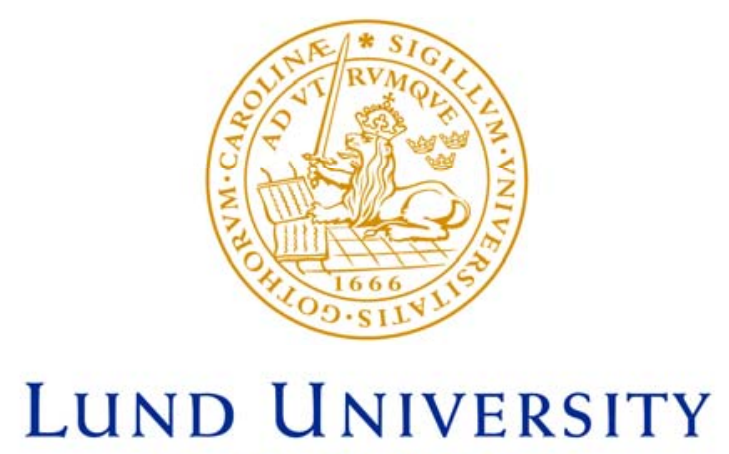

Faculty of Medicine

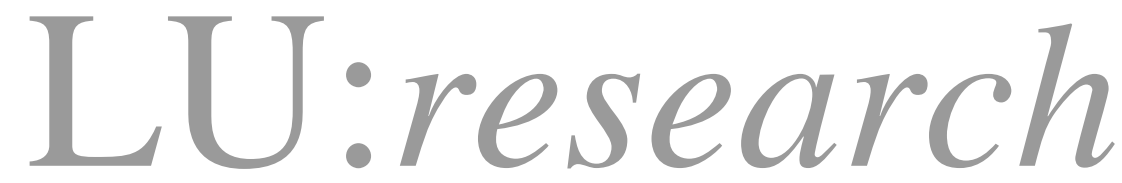

Institutional Repository of Lund University

This is an author produced version of a paper published in Intensive \& critical care nursing: the official journal of the British Association of Critical Care Nurses. This paper has been peer-reviewed but does not include the final publisher proof-corrections or journal pagination.

Citation for the published paper:

Corrigan, Ingrid and Samuelson, Karin A M and Fridlund, Bengt and Thomé, Bibbi.

"The meaning of posttraumatic stress-reactions following critical illness or injury and intensive care treatment" Intensive Crit Care Nurs, 2007, Vol: 23, Issue: 4, pp. 206-15.

http://dx.doi.org/10.1016/j.iccn.2007.01.004

Access to the published version may

require journal subscription.

Published with permission from: Elsevier 


\section{THE MEANING OF POSTTRAUMATIC STRESS-REACTIONS FOLLOWING CRITICAL ILLNESS OR INJURY AND INTENSIVE CARE TREATMENT}

\section{Ingrid Corrigan, RNIC, MScN}

RNIC, Intensive Care Unit, Division of Anaesthesiology and Intensive Care, Lund University Hospital, SE-221 85 Lund, Sweden

Tel no: 004646 171019, e-mail: ingrid.corrigan@lsn.se

Karin AM Samuelson, RNANIC, MScN, Doctoral Student

Doctural Student, Division of Nursing, Department of Health Sciences, Lund University, P.O. Box 157, SE-221 00 Lund, Sweden

Bengt Fridlund, RNAN, RNT, PhD, Professor

Professor, School of Health Sciences and Social Work, Växjö University, SE-351 95 Växjö, Sweden

Bibbi Thomé, RNT, PhD, Senior Lecturer

Senior Lecturer, Division of Nursing, Department of Health Sciences, Lund University, P.O. Box 157, SE-221 00 Lund, Sweden

Reprint requests to Ingrid Corrigan 


\section{ABSTRACT}

Traumatic events connected with a critical condition and treatment in the intensive care unit (ICU) may result in subsequent posttraumatic stress-reactions. The aim of this phenomenological study was to describe the meaning of posttraumatic stress-reactions as experienced by individuals following a critical illness or injury and intensive care. Fourteen informants, testing positive for posttraumatic stress-reactions as a clinical concern, were interviewed. The data was analysed following the principles indicated by Giorgi (1997). The essence of the phenomenon of posttraumatic stress-reactions was understood as a transition to a life-situation beyond control, where the traumatic experiences have a profound impact and are ever-present. The variations of the phenomenon presented themselves as a need to make sense of the traumatic memories, which live on; being haunted by the trauma; a need to escape; distress and strain in the life-situation; transformation of self and, finally, interactions with others affected. The need for caring strategies and support is emphasised, both in the ICU and afterwards, thus preventing or alleviating some of the suffering. 


\section{INTRODUCTION}

A serious illness or injury, and treatment in the ICU, can be very stressful experiences (Granberg et al., 1998; Rotondi et al., 2002; Russell, 1999; Stein-Parbury and McKinley, 2000). A wide range of stressors, e.g. pain and being restricted by tubes, add to the distress (Biancofiore et al., 2005; Novaes et al., 1999). The condition is frequently life-threatening, contributing to feelings of anxiety and fear (Granberg et al., 1999; Rotondi et al., 2002). Some patients develop acute confusion as well as unreal experiences, hallucinations and nightmares (Granberg et al., 1999; Granja et al., 2005; Magarey and McCutcheon, 2005; Roberts and Chaboyer, 2004), which are likely to have a high emotional impact (Jones et al., 2001).

For some patients, the stress-reaction may become traumatic, affecting a range of psychobiological processes, including the memory systems (van der Kolk, 1996a). Memories of traumatic events may be encoded differently in the brain than memories of ordinary events. Thus, the traumatic experience can remain etched in the mind well into the future (van der Kolk, 1996b, Van der Kolk and McFarlane, 1996). In the long-term, factual memories may persist as well as memories of unreal experiences, hallucinations and nightmares (Löf et al., 2006; Rundshagen et al., 2002; van de Leur et al., 2004), which are referred to as delusional memories (Jones et al., 2001; Skirrow, 2002).

As a consequence of traumatic experiences, individuals may develop acute stress disorder (ASD) (American Psychiatric Association, 1994). If the symptoms remain for more than a month and meet certain criteria, posttraumatic stress disorder (PTSD) is 
said to occur. PTSD is a serious anxiety disorder, occurring in individuals who have been exposed to an event entailing actual or threatened death or serious injury, the response to which involved fear, helplessness or horror (American Psychiatric Association, 1994). PTSD is characterized by three key features: intrusive, avoidant and hyperarousal symptoms. The intrusive symptoms include recurrent flashbacks and nightmares, giving the sense of reliving the traumatic event. These symptoms are often accompanied by intense psychological and physical distress. The individual persistently tries to avoid reminders of the trauma, as well as associated thoughts or activities. The hyperarousal symptoms include difficulty sleeping, irritability and outbursts of anger, as well as problems concentrating (American Psychiatric Association, 1994).

The formal diagnosis of PTSD, according to the Diagnostic \& Statistical Manual of Mental Disorders-IV (DSM-IV), requires a precise number of criteria to be met (American Psychiatric Association, 1994). Some individuals, however, have clinicallysignificant PTSD symptoms but do not meet the full set of criteria required for PTSD (Mylle and Maes, 2004). In the absence of a formal diagnosis, terms like posttraumatic stress-reactions are used (Dyb et al., 2003).

Recognizing that a critical condition and ICU treatment can constitute a traumatic event, PTSD (or posttraumatic stress-reactions) in these patients has been studied, by reporting prevalence rates, for instance (Cuthbertson et al., 2004; Nickel et al., 2004; Schnyder et al., 2001; Scragg et al., 2001; Tedstone and Tarrier, 2003), or associating posttraumatic stress-reactions with traumatic memories, e.g. factual or delusional (Capuzzo et al., 2005; Jones et al., 2001; Schelling et al., 2003). However, to our knowledge, no 
qualitative studies have been undertaken. Therefore, little is known of the lived experience of posttraumatic stress-reactions and the meaning that individuals attach to this phenomenon. An increased level of understanding could give useful feedback to staff caring for patients in the ICU, thus improving the care and support provided to these individuals, both during and after the ICU-period. Consequently, the aim of this study was to describe the meaning of posttraumatic stress-reactions as experienced by individuals following a critical illness or injury and intensive care.

\section{METHOD}

\section{Philosophical orientation}

The philosophical foundation of this study was the phenomenological approach, which turns to the world as it is experienced, in all its variety (Dahlberg et al., 2001). In turning to lived experience, phenomenology provides concrete insights into what it means to experience an illness, for instance (Toombs, 2001). The lifeworld is a central theme of phenomenology and "the overall aim of lifeworld research is the description and elucidation of the lived world in a way that expands our understanding of human experience" (Dahlberg et al., 2001 p. 49). The phenomenological idea of going to the things themselves, according to Husserl (1970), entails doing justice to the lived experience. Posttraumatic stress-reactions can be understood as a phenomenon of the world as it is experienced by a subject. Phenomenology looks at the way in which that is experienced, as a phenomenon, in order to grasp the meaning of that phenomenon, which is then described as faithfully as possible (Dahlberg et al., 2001). 
Giorgi $(1985,1997)$ indicates three criteria necessary for phenomenological research in a descriptive Husserlian sense. The first criterion is detailed and concrete descriptions of lived experiences from others, characterized by the natural attitude of everyday life. The second is the phenomenological reduction, which means withholding past knowledge about the phenomenon (i.e. bracketing) in order to be fully present to descriptions of the phenomenon as presented by the subjects, allowing it to be seen as it presents itself. Any belief that the phenomenon actually is what it is has to be set aside. Thirdly, there must be a search for scientific essences, which are contextual and which depend on the disciplinary framework. This process, based on imaginative or experiential variations of a phenomenon, involves searching for and imagining variations in the data in order to clearly see the essence or general structure. The essential meaning of the phenomenon is "a fundamental meaning without which a phenomenon could not present itself as it is" (Giorgi, 1997 p. 242).

\section{Informants}

The informants were enrolled from another study (Samuelson et al., 2007), in which mechanically ventilated ICU-patients being treated in general ICUs for at least 24 hours participated. Two months following discharge from the ICU, those persons $(n=226)$ were tested using the Impact of Event Scale-Revised (IES-R) (Weiss and Marmar, 1997). The IES-R is a screening device for PTSD, assessing the current subjective distress (intrusion, avoidance and hyperarousal-symptoms) after a traumatic event. A cut-off value of 30 (IES-R range 0-88) has proved useful in identifying individuals with posttraumatic stress-reactions as a clinical concern (Asukai et al., 2002). 
In connection with the IES-R testing, those scoring $\geq 30$ on the IES-R $(n=20)$ were asked if they had any objections to receiving a letter containing information about this study. All, apart from one, accepted and were thus informed by letter. The first author then asked them by phone if they wished to participate. Five patients declined, leaving 14, i.e. 11 women and 3 men, with a median age of 52 (range 42-74). The reasons for the ICU admissions were: primary medical, major surgery or postoperative complications and multiple trauma. The median time spent in the ICU was 5 days (range 1-35) and the median IES-R score was 41 (interquartile range 15) range 30-83.

\section{Procedure}

Following a pilot interview, 14 informants were interviewed. The interviews were undertaken between December 2003 and March 2005, at a time and in a setting chosen by the informant, most often at home. The median time-span between the IES testing and the interview was nearly 2 months (range 1-19.5). The interviews, which were unstructured, were conducted by the first author. They commenced by asking the informants to describe their feelings upon falling ill and being admitted to the ICU, as it was considered relevant to hear their perception of the traumatic experiences in order to increase understanding of the subsequent reactions to these experiences. The focal point was then gently shifted towards the focus of the interview, i.e. how the person felt and what his or her life-situation was like in the aftermath of the traumatic experiences. The informants were encouraged to talk freely and without interruption, apart from when asked to expand upon their train of thought. The interviews lasted between one and a half and three hours. They were tape-recorded and subsequently transcribed verbatim by the first author. 


\section{$\underline{\text { Ethical considerations }}$}

This study was approved by the Ethics Committee of Lund University, Sweden (LU 929-03). Informed consent was obtained both verbally and in writing. The informants, who were not dependent on the researchers in any way, were informed about the voluntary aspect of participating and guaranteed the freedom to terminate the interview at any time. They were also assured that their confidentiality would be preserved throughout the entire research process. During the interviews, the researcher tried to be as sensitive and respectful as possible vis-à-vis the informants, who were often in a vulnerable and emotional situation. However, the opportunity to talk about experiences and feelings seemed to be welcomed. A couple of participants showed signs of wanting or needing psychological help and were consequently referred to psychiatric clinics for professional counselling. 


\section{Data analysis}

The first author's pre-understanding as an intensive care nurse working in an ICU follow-up clinic was reflected upon, made explicit and, finally, bracketed in order to remain open and sensitive to the phenomenon throughout the entire process.

The analysis, which commenced after the last interview, was done in collaboration with all authors, especially the last author, and followed the principles indicated by Giorgi (1997). At the beginning, the text was read a number of times to obtain a sense of the whole and to open up the mind to what was actually there. The text was then divided into meaning units in relation to the change of meaning or idea in the text. In order to understand the meaning of every unit, questions relating to the aim of the study were set to the text, whilst observing similarities and differences. Subsequently, the expressions of the informants from the natural attitude were transformed into the disciplinary language, with the focus on the phenomenon, so that the content could be expressed from a scientific perspective, i.e. nursing science. Various meanings of the phenomenon were elucidated and then organized into clusters, which were linked together in order to understand patterns. Next, the meanings were synthesized into a structure binding them together, moving towards a more abstract level of understanding and arriving at some structure whereby the essence of the phenomenon, and its variations, could be described. Finally, the original text was reread in its entirety in order to ensure that the data was emptied of its meanings.

Figure 1 here 


\section{FINDINGS}

A brief description is given regarding the informants' perceptions of their traumatic experiences, and their situations at the time of the interviews, followed by the findings revealed by the phenomenological analysis.

The informants described a wide range of traumatic experiences. Despite this wide range, helplessness and fear were common denominators. A few of the informants were unfazed about their ICU stay, instead experiencing traumas either beforehand or afterwards, e.g. in connection with dental treatment, an accident or serious complications. However, most informants experienced the ICU as extremely distressing. Breathing difficulties, as well as activities connected with patient care, were experienced as traumatic ordeals. In some cases, staff were felt to have acted in an arrogant and unprofessional manner, adding to the distress. Various other stressors, e.g. extreme pain, were felt to be very troublesome. Frightening unreal experiences, hallucinations and nightmares often contained themes of a brutal death and had a traumatic impact. A few informants had no factual recall from the ICU, or some of the preceding events. At the time of the interviews, many informants were suffering from lasting physical difficulties, following their critical illness or injury, which entailed changes in the life-situation. 


\section{The essence of the phenomenon and its variations}

The phenomenological analysis revealed the essence of the phenomenon of posttraumatic stress-reactions, which was understood as a transition to a life-situation beyond control, where the traumatic experiences have a profound impact and are everpresent. Six variations presented themselves: a need to make sense of the traumatic memories, which live on; being haunted by the trauma; a need to escape; distress and strain in the life-situation; transformation of self and, finally, interactions with others affected (see Fig. 2), which will subsequently be described.

Figure 2 here

\section{A need to make sense of the traumatic memories, which live on}

The traumatic memories were still very vivid and painful after several months. It felt like having lived through a nightmare, making it quite impossible to ever fully recover. The delusional memories were especially stressful. These really seemed to be imprinted on the memory, compared to normal dreams or nightmares which usually faded with time. Understanding the unreal experiences, hallucinations or nightmares was expressed as a real need:

all the time busy with these in my thoughts, I replayed them the whole time and I just felt worse and worse ...[...]... because it tormented me so much that I felt I needed clarity (Int 2)

Even though they could not logically be accurate, they still gave a sense of actually having lived in their midst. Sometimes, it was impossible to work out whether they were real or not. 
Having no memories of what happened in the ICU meant relief for some. For others, however, the memory loss proved to have a severe impact:

it's as if somebody has taken these days ... this time from me ... they've just pulled them away and I don't know anything ... it's as if I, I was completely gone then, I didn't exist during that time ... it puts things on hold, you can't really move on (Int 8)

Constantly thinking about what had happened, as well as how, proved to be characteristic of the months following the traumatic experiences. However, despite the constant thoughts attempting to form a clear picture and bring some understanding, there was a feeling of being unable to make any sense of it:

no matter how much I think about it myself, I still can't get a clear picture (Int 5)

\section{Being haunted by the trauma}

There was a sense of being haunted, manifesting itself in various ways. Feelings and thoughts relating to the traumatic experiences were uncontrollable, frequently intruding into the life-situation. It felt like the traumatic experiences had to be relived over and over again, triggering profound distress:

it's the intensive care that's the worst ... that period haunts me (Int 4)

Various cues, e.g. TV programmes or the hospital, appeared as reminders, triggering exactly the same emotions felt during the traumatic experiences:

it's enough that someone says something on the radio, mentions the term intensive care or something, or when you watch teletext or TV and that word crops up, or there's a nurse working with ... at the ICU, ugh, then I feel exactly like I did then (Int 4)

In addition, vivid images of the traumatic experiences were felt to be totally uncontrollable. This was experienced like extremely clear film-sequences, which 
suddenly started playing, triggering severe distress. Rapid flashbacks were also experienced, as quick as lightning and lasting only a split second:

these pictures come like a bolt out of the blue (Int 6)

Nightmares were frequent, mostly consisting of themes from the traumatic experiences, causing abrupt awakenings accompanied by feelings of despair and panic.

Feelings of being haunted by recent traumatic experiences also reawakened previouslyexperienced traumas, e.g. sexual violation during childhood. Earlier problems or grievances were intensified, adding to the burden and increasing the level of suffering:

when my husband died, it's true that it's 15 years ago ... but it gets to me a lot, a lot more now ... than it did before (Int 13) 


\section{A need to escape}

Certain thoughts and actions connected with the traumatic experiences nearly always had to be avoided and escaped from as they caused anxiety. However, despite every effort, it mostly proved impossible to escape from these thoughts:

thoughts go round in my head all the time ... I can't keep them at bay (Int 10)

Reminders of traumatic ordeals also had to be avoided, further restricting the lifesituation. This manifested itself in various actions ranging from being unable to watch certain TV programmes to having to move house. It felt like running for one's life. Everyday activities, e.g. going to the dentist or meeting people, were unthinkable. Consequently, daily life was rearranged accordingly:

I avoided catching a glimpse of the hospital, under any circumstances, and that isn't easy ...[...]... so there have been some lengthy detours (Int 2)

In addition, the fear of the trauma repeating itself was coupled with a deep-seated need to avoid this. Various measures, e.g. scrupulously managing medication, had to be taken in order to avoid another traumatic experience.

\section{Distress and strain in the life-situation}

Distress showed itself in bodily signs. The mere thought of the traumatic experiences and the sense of reliving them meant physical reactions, e.g. shivering, cold sweats and palpitations. However, these physical symptoms sometimes appeared for no apparent reason and were experienced as extremely distressful. Fatigue and frailty added to the feeling of being off-balance. This could not be slept off and was experienced as 
overwhelming. Sleep was greatly disturbed, manifesting itself in various ways. Going to bed was frightening:

I spend the entire afternoon dreading the evening ... ugh, I think to myself, the hell is beginning all over again (Int 4)

Falling asleep was found to be very difficult, despite severe tiredness. Losing control was felt to be hard, as sleep meant vulnerability to horrifying nightmares. Thoughts went round and round:

can't say what keeps me awake ... it's just that ... I really feel ... I can't relax at all ... there are a thousand and one thoughts in my head (Int 11)

Sleep medication had to be used but did not always work. If sleep was possible at all, it did not last long before being disrupted by abrupt awakenings.

Emotional distress manifested itself through, for instance, frequent mood swings.

Irritation and anger, as well as anxiety and despair, could suddenly erupt:

I cried for the slightest reason ... it ... only took the smallest setback (Int 10)

Occasionally, sedatives were necessary. Emotional distress also presented itself in feelings of suffering a major loss. There was a sense of feeling let down by life itself.

The life-situation was strongly affected by fear, which manifested itself in various ways. Thoughts about having to undergo the trauma again meant a fear so strong that it led to feelings of panic. Having to endure an operation and intensive care again, for instance, was talked about as a horrifying prospect:

I just walk around thinking, what happens if I get sick and have to have emergency surgery ... I'd almost be on the verge of committing suicide instead (Int 4) 
The joy of life was felt to have disappeared. Some days, apathy dominated and strength was totally lacking. Life was felt to have been ruined, with hope and meaning missing from the life-situation. Instead, everything was dark and difficult and there was a longing for these dreadful days to end as quickly as possible. At times, feelings of worthlessness and depression took on existential undertones:

why do I exist, sort of thing ... what, what's the point of all this? (Int 11)

There was a fear of dying, however, death was sometimes felt to be a way out of a very difficult situation:

sometimes in the evenings I've thought to myself ... "hell, it would have been better to have slipped away" ... then you feel nothing (Int 14)

Mental strain showed itself as there was a sense of being unable to function normally.

Concentrating was felt to be difficult and feelings of confusion manifested themselves.

Severe memory disturbances meant profound disruptions to the life-situation.

Information was impossible to assimilate and it was not feasible to relate anything.

These problems caused a sense of loneliness, as well as frustration and despair:

it was terrible ... God knows how many times a day I just sat ... and cried ... that was probably the most difficult thing of all ... I was completely convinced I was going mad (Int 3)

\section{Transformation of self}

The profoundly affected life-situation meant a transformation of self. This was interpreted as having undergone the transition to a different person, to an unrecognisable extent. Emotional turmoil was now a characteristic feature and the transformation was reflected upon: 
previously I was a harmonious, calm, positive and stable person, now things are different ...

I'm more insecure and nervous, which I wasn't before (Int 15)

In contrast, being transformed as a person manifested itself in feelings of numbness and indifference, feelings that could neither be recognized nor understood:

it feels like you've been given a sedative (Int 4)

The spiritual dimension of life, involving a firm belief in higher powers and life after death, was felt to have been lost. New value systems were developing; life could not be taken for granted and good health was appreciated as never before. Things that used to be important now had no meaning whatsoever.

\section{Interactions with others affected}

Interactions with loved ones were affected, in that it sometimes felt hard to give and receive love. At times, the family seemed to lack understanding, adding to the distress already felt. However, the love and concern of the family was realized like never before. Family members were often felt to be supportive, but there was a strong sense of not wanting to become a burden. There were also feelings of having let the family down by putting them through so much agony:

I've let them down ... yes, I feel I've let them down ...[...]... yes I have, I think, a ... big, heavy burden to shoulder ... but when I tell them this, they really can't understand how I can feel that way (Int 12)

People in general proved to have no idea of what it really felt like, which sometimes led to a reluctance to interact socially. There were feelings of not being understood:

they tell me "yes K, you'll soon be fine, you look well” ... but they didn't know how I felt, I wasn't as well as they thought (Int 7) 
Withdrawing and isolating oneself also meant that well-intentioned questions could be avoided. However, this increased the feeling of sadness and further limited the lifesituation. Being alone was talked about both in terms of a fear and a need for solitude.

\section{DISCUSSION}

\section{Methodological aspects}

Lincoln and Guba (1985) have outlined certain criteria in order to establish trustworthiness in qualitative studies. Credibility refers to confidence in the truth of the data through conducting the investigation in such a way that the believability of the findings is enhanced (Lincoln and Guba, 1985). Prolonged engagement refers to sufficient time being spent on collecting the data in order to get an in-depth understanding. Persistent observation concerns the researcher's ability to focus on aspects relevant to the specific phenomenon (Lincoln and Guba, 1985). To endorse these aspects during this study, all the interviews were conducted by the same researcher, who tried to build trust and make it easy for the often very emotional informants to tell their stories and reflect on the phenomenon in their own time. The lengthy interviews produced rich data. According to Dahlberg et al. (2001), high quality data is required to reach a result that is a new understanding.

Taking steps to demonstrate credibility is also important (Lincoln and Guba, 1985) as is presenting a thorough inner logic whereby it is possible to follow the researcher's reasoning throughout the entire process (Dahlberg et al., 2001). In this study, clarifying 
the research process and using quotations to illustrate the findings constitute examples of such measures. Repeated discussions were held between the authors concerning the meaning of the data, thereby further strengthening credibility. The authors had divergent perspectives, thus moderating the possible influence of the first author's preunderstanding. Transferability refers to the generalizability of the data. In providing "thick descriptions", an evaluation can be made by others regarding the applicability to other contexts (Lincoln and Guba, 1985). However, phenomenological research is always contextual and can never be understood as universal, even if the result is lifted above the concrete level (Dahlberg et al., 2001).

The phenomenological notion of Husserl (1970), i.e. of going to the things themselves, in this study means going back to the suffering patients themselves, back beyond the theory of a disorder to the experiences of the patients suffering from the disorder, i.e. illness-as-lived (Toombs, 2001). Thus, this study is an attempt to describe the lived experience of posttraumatic stress-reactions, in all its complexity, following a critical illness or injury and intensive care. However, it is unlikely that this phenomenon alone is described without the influence of other predicaments. Some informants' lifesituations were strongly affected by physical difficulties, for instance, which could have impacted upon their life-situations. However, it would be difficult to make a clear distinction between posttraumatic stress-reactions and symptoms attributable to other predicaments. Furthermore, in comparison to the DSM-IV criteria for PTSD (American Psychiatric Association, 1994), the findings are in accordance with most PTSD symptoms. Other factors could have influenced the findings: the selection of informants by using a cut-off of the IES-R, for instance, might not have been adequate to identify 
individuals with posttraumatic stress-reactions (Weiss, 2004). However, support has been published for a similar, albeit slightly higher, cut-off (Creamer et al., 2003).

\section{Aspects of the findings}

The meaning of the phenomenon of posttraumatic stress-reactions is expressed in the essence of the phenomenon, and its variations. Thus, the essence presents itself as a transition to a life-situation beyond control, where the traumatic experiences have a profound impact and are ever-present. For the informants, the transition consisted of a major change in their life-situation, entailing a great deal of suffering.

Ordinary memories are usually re-experienced in their "pastness" (Casey, 2000). Traumatic memories, however, are timeless and do not fade with time like normal memories (van der Kolk, 1996a; Van der Kolk and McFarlane, 1996). For the informants in this study, the traumatic memories were vividly imprinted and had "stuck", giving a strong sense of being haunted and having to relive the traumatic experiences again and again. Consequently, there was temporal (lived time) disparity in the sense that the past actually overrode the present. The delusional memories had an especially severe impact, as documented in several studies (Granberg et al., 1999; Granja et al., 2005; Löf et al., 2006; Magarey and McCutcheon, 2005; Roberts and Chaboyer, 2004; Rundshagen et al., 2002). Additionally, delusional memories have been linked with posttraumatic stress-reactions (Jones et al., 2001).

Having to avoid certain activities, which acted as reminders of the traumatic experiences, shrank the lived space considerably for the informants. However, despite 
all the efforts aimed at avoiding activities or situations, there was a strong sense of not being able to get away. The post-ICU recovery period has been characterized by “moving on", e.g. leaving behind the ICU experience (Maddox et al., 2001). This does not seem to apply to those suffering from posttraumatic stress-reactions, as the traumatic memories hinder this "moving on".

The world is perceived with our bodies, which are the carriers of experiences, according to Merleau-Ponty (1962). It is possible that his notions, that meaning is experienced directly in our bodies and that a person's body-mind is an indissoluble unity (Thomas, 2005), has been illustrated in this study. Every mental activity of the informants regarding their traumatic experiences, e.g. intrusive thoughts, was instantly felt in the body. Thus, the posttraumatic stress-reactions became embodied, escalating the distress.

Emotional distress was experienced; fear was especially prominent, both in connection with the actual trauma and during the life-situation afterwards. The fear of the trauma repeating itself was significant, to the extent that suicide was contemplated as an alternative to facing another traumatic ordeal. This example sheds light upon the impact and horror of a traumatic experience. Signs of depression also manifested themselves as some informants described a life-situation without hope and meaning. This is not surprising, as depression is a well-known co-morbidity in PTSD (O'Donnell et al., 2004), increasing the general distress (Shalev, 2001).

The informants experienced a transformation of self that was beyond recognition. In addition, the spiritual dimension of the life-situation was felt to have been lost. These findings are contrary to those of Papathanassoglou and Patiraki (2003), who 
demonstrated transformation of self in a more positive meaning, e.g. entailing personal growth and spiritual arousal, in survivors of critical illness. Suffering from posttraumatic stress-reactions seems to bring about change as well as loss, e.g. of one's former self and spirituality.

\section{Conclusions and implications}

This phenomenological study attempts to contribute to a holistic understanding of the lived experience of posttraumatic stress-reactions following critical illness or injury and intensive care. The findings suggest that the suffering by these individuals is substantial, emphasizing the need for empathetic care in the ICU as well as afterwards. In the ICU, it is very important to lessen the impact of the stressors. By reducing the patient's distress and fear, the impact and perception of the trauma could be lessened. Besides pharmacological means, the ICU nurse plays a vital role in e.g. facilitating communication, repeatedly explaining events, providing reality links as well as offering constant reassurances and emotional support. Moreover, efforts to keep the ICU environment as calm as possible and encouraging the family to be present are other important steps in relieving the patient's distress. Consequently, when these caring and supportive strategies are offered, the patient's stress might not become traumatic, with the attendant risk of traumatic memories forming which could cause posttraumatic stress-reactions later on.

In addition, this study emphasizes the need for follow-up services, possibly including screening for posttraumatic stress-reactions. The follow-up team needs to be able to identify patients suffering from posttraumatic stress-reactions in order to offer support, 
from a caring and holistic perspective, and to make referrals to counsellors or psychologists. More research is needed in order to further understand the meaning of posttraumatic stress-reactions and also to study effective means of identifying those suffering from this phenomenon following a critical illness or injury and intensive care. 


\section{REFERENCES}

American Psychiatric Association. Diagnostic and Statistical Manual of Mental

Disorders, 4th ed. DSM-IV. Washington, DC: American Psychiatric Association; 1994.

Asukai N, Hiroshi K, Kawamura N, Kim, Y, Yamamoto K, Kishimoto J, et al. Reliability and validity of the Japanese-language version of the Impact of Event Scale-Revised (IES-R): four studies of different traumatic events. J Nerv Ment Dis 2002; 190: 175-182.

Biancofiore G, Bindi ML, Romanelli AM, Urbani L, Mosca F, Filipponi F. Stressinducing factors in ICUs: what liver transplant recipients experience and what caregivers perceive. Liver Transpl 2005; 11: 967-72.

Capuzzo M, Valpondi V, Cingolani E, Gianstefani G, De Luca S, Grassi L, et al. Posttraumatic stress disorder-related symptoms after intensive care. Minerva Anestesiol 2005; 71: 167-79.

Casey ES. Remembering. A phenomenological study. Bloomington: Indiana University Press; 2000.

Creamer M, Bell R, Failla S. Psychometric properties of the Impact of Event ScaleRevised. Behav Res Ther 2003; 41: 1489-96.

Cuthbertson BH, Hull A, Strachan M, Scott J. Post-traumatic stress disorder after critical illness requiring general intensive care. Intensive Care Med 2004; 30: 450-5.

Dahlberg K, Drew N, Nyström M. Reflective lifeworld research. Lund: Studentlitteratur; 2001. 
Dyb G, Holen A, Braenne K, Indredavik MS, Aarseth J. Parent-child discrepancy in reporting children's post-traumatic stress reactions after a traffic accident. Nord J Psychiatry 2003; 57: 339-44.

Giorgi A. Sketch of a psychological phenomenological method. In: Giorgi A, editor. Phenomenology and psychological research. Pittsburgh: Duquesne University Press; 1985. p. 8-22.

Giorgi A. The theory, practice, and evaluation of the phenomenological method as a qualitative research procedure. Journal of Phenomenological Psychology 1997; 28: $235-61$.

Granberg A, Bergbom-Engberg I, Lundberg D. Patients' experience of being critically ill or severely injured and cared for in an intensive care unit in relation to the ICU syndrome. Intensive Crit Care Nurs 1998; 14: 294-307.

Granberg A, Bergbom-Engberg I, Lundberg D. Acute confusion and unreal experiences in intensive care patients in relation to the ICU syndrome. Intensive Crit Care Nurs 1999; 15: 19-33.

Granja C, Lopes A, Moreira S, Dias C, Costa-Pereira A, Carneiro A, et al. Patients' recollections of experiences in the intensive care unit may affect their quality of life. Crit Care 2005; 9: R96-109.

Husserl E. Logical investigations: vol 1. Prolegomena to pure logic. London: Routledge \& Kegan Paul; 1970.

Jones C, Griffiths RD, Humphris G, Skirrow PM. Memory, delusions, and the development of acute posttraumatic stress disorder-related symptoms after intensive care. Crit Care Med 2001; 29: 573-80.

Lincoln YS, Guba EG. Naturalistic inquiry. Newbury Park: Sage; 1985. 
Löf L, Berggren L, Ahlström G. Severely ill ICU patients recall of factual events and unreal experiences of hospital admission and ICU stay-3 and 12 months after discharge. Intensive Crit Care Nurs 2006; 22: 154-66.

Maddox M, Dunn SV, Pretty LE. Psychosocial recovery following ICU: experiences and influences upon discharge to the community. Intensive Crit Care Nurs 2001; 17: 6-15.

Magarey JM, McCutcheon HH. "Fishing with the dead"-Recall of memories from the ICU. Intensive Crit Care Nurs 2005; 21: 344-54.

Merleau-Ponty M. Phenomenology of perception. London: Routledge \& Kegan Paul; 1962.

Mylle J, Maes M. Partial posttraumatic stress disorder revisited. J Affect Disord 2004; 78: $37-48$.

Nickel M, Leiberich P, Nickel C, Tritt K, Mitterlehner F, Rother W, et al. The occurrence of posttraumatic stress disorder in patients following intensive care treatment: a cross-sectional study in a random sample. J Intensive Care Med 2004; 19: 285-90.

Novaes MAFP, Knobel E, Bork AM, Pavao OF, Nogueira-Martins LA, Ferraz MB. Stressors in the ICU: perception of the patient, relatives and health care team. Intensive Care Med 1999; 25: 1421-6.

O’Donnell ML, Creamer M, Pattison P. Posttraumatic stress disorder and depression following trauma: understanding comorbidity. Am J Psychiatry 2004; 161: 1390-6.

Papathanassoglou EDE, Patiraki EI. Transformations of self: a phenomenological investigation into the lived experience of survivors of critical illness. Nurs Crit Care 2003; 8: 13-21. 
Roberts B, Chaboyer W. Patients' dreams and unreal experiences following intensive care unit admission. Nurs Crit Care 2004; 9: 173-80.

Rotondi AJ, Lakshmipathi C, Sirio C, Mendelsohn A, Schulz R, Belle S, et al. Patients' recollections of stressful experiences while receiving prolonged mechanical ventilation in an intensive care unit. Crit Care Med 2002; 30: 746-52.

Rundshagen I, Schnabel K, Wegner C, Schulte am Esch J. Incidence of recall, nightmares, and hallucinations during analgosedation in intensive care. Intensive Care Med 2002; 28: 38-43.

Russell S. An exploratory study of patients' perceptions, memories and experiences of an intensive care unit. J Adv Nurs 1999; 29: 783-91.

Samuelson K, Lundberg D, Fridlund B. Stressful memories and psychological distress in adult mechanically ventilated intensive care patients - a 2-month follow-up study. ACTA Anaesthesiol Scand 2007; 51: 1-8.

Schelling G, Richter M, Roozendaal B, Rothenhäusler H-B, Krauseneck T, Stoll C, et al. Exposure to high stress in the intensive care unit may have negative effects on health-related quality-of-life outcomes after cardiac surgery. Crit Care Med 2003; 31: 1971-80.

Schnyder U, Moergeli H, Klaghofer R, Buddeberg C. Incidence and prediction of posttraumatic stress disorder symptoms in severely injured accident victims. Am J Psychiatry 2001; 158: 594-9.

Scragg P, Jones A, Fauvel N. Psychological problems following ICU treatment. Anaesthesia 2001; 56: 9-14.

Shalev AY. What is post-traumatic stress disorder? J Clin Psychiatry 2001; 62 (Suppl 17): 4-10. 
Skirrow P. Delusional memories of ICU. In: Griffiths RD, Jones C, editors. Intensive Care Aftercare. Oxford: Butterworth-Heinemann; 2002. p. 27-35.

Stein-Parbury J, McKinley S. Patients' experiences of being in an intensive care unit: a select literature review. Am J Crit Care 2000; 9: 20-7.

Tedstone JE, Tarrier N. Posttraumatic stress disorder following medical illness and treatment. Clin Psychol Rev 2003; 23: 409-48.

Thomas SP. Through the lens of Merleau-Ponty: advancing the phenomenological approach to nursing research. Nurs Philos 2005; 6: 63-76.

Toombs SK. Introduction: Phenomenology and medicine. In: Toombs SK, editor. Handbook of phenomenology and medicine. Dordrecht: Kluwer Academic Publishers; 2001. p. 1-26.

Van der Kolk BA. The body keeps the score. Approaches to the psychobiology of posttraumatic stress disorder. In: van der Kolk BA, McFarlane AC, Weisath L, editors. Traumatic stress: the effects of overwhelming experience on mind, body, and society. New York: Guilford Press; 1996a. p. 214-41.

Van der Kolk BA. Trauma and memory. In: van der Kolk BA, McFarlane AC, Weisath L, editors. Traumatic stress: the effects of overwhelming experience on mind, body, and society. New York: Guilford Press; 1996b. p. 279-302.

Van der Kolk BA, McFarlane AC. The black hole of trauma. In: van der Kolk BA, McFarlane AC, Weisath L, editors. Traumatic stress: the effects of overwhelming experience on mind, body, and society. New York: Guilford Press; 1996. p. 3-23.

Van de Leur JP, van der Schans CP, Loef BG, Deelman BG, Geertzen JHB, Zwaveling JH. Discomfort and factual recollection in intensive care unit patients. Crit Care 2004; 8: R467-73. 
Weiss DS. The Impact of Event Scale-Revised. In: Wilson JP, Keane TM, editors.

Assessing psychological trauma and PTSD. $2^{\text {nd }}$ edition. New York: Guilford Press; 2004. p. 168-89.

Weiss DS, Marmar CR. The Impact of Event Scale-Revised. In: Wilson JP, Keane TM, editors. Assessing psychological trauma and PTSD. New York: Guilford Press; 1997. p. 399-411. 
Figure 1

Schematic description of the analysis, following the principles of Giorgi (1997).

\begin{tabular}{||c||c||c||c||c||}
\hline Reading \\
of the \\
data as a
\end{tabular}

Figure 2. The essence of the phenomenon and its variations

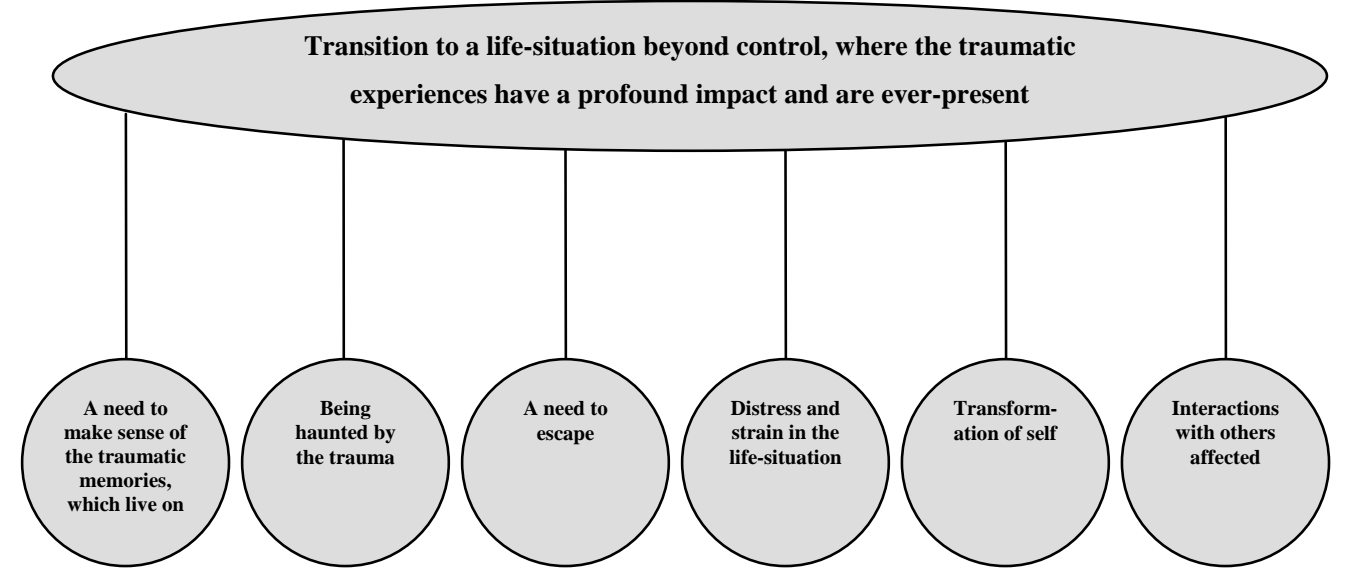

